\title{
Mitochondrial DNA Inheritance Mystery
}

\author{
Irfan Afzal Mughal
}

Associate Professor, Department of Physiology, HBS Medical College, Islamabad, Pakistan

Mitochondrial DNA (mtDNA) was discovered in 1963. Its inheritance was labeled as maternal type. Some selective mechanisms are still mysterious, that how paternal mtDNA is selectively destroyed. Marking of ubiquitin to sperm mitochondria facilitates the deselection of paternal mitochondrial DNA molecules. After fertilization (four to eight-cell stage) paternal mtDNA is not detected usually. Recently the concept of mixed mtDNA haplotype was found, which suggests biparental mtDNA inheritance. $^{1}$

Previously it was hypothesized that paternal mtDNA molecules were diluted in the fertilized egg. Later, in unicellular alga Chlamydomonas and Medaka fish, mtDNA was found to be eliminated after fertilization. ${ }^{2}$ This theory remained under discussion for decades. Researchers described the role of mitophagy in the selective elimination of paternal mitochondria. $^{3}$

Principally, the paternal inheritance from sperm mitochondria to egg at fertilization is 1,000 -fold less than the mitochondrial number in the oocyte. There is always an inevitable sexual conflict in the competition between paternal and maternal mitochondrial inheritance, which suggests that paternal leakage and presence of heteroplasmy is

\section{Correspondence:}

Irfan Afzal Mughal

Email:the.mughal@hotmail.com

Cite this editorial: Mughal IA. Mitochondrial DNA Inheritance Mystery. J Islamabad Med Dental Coll. 2020; 9(3): 153-154

Doi: $10.35787 /$ jimdc.v9i3.606 due to this sexual conflict. In healthy people, heteroplasmy i.e. presence of more than one mtDNA type, is common and this can increase with the advancing age, as there are more chances of mutations. ${ }^{4}$

In a recent study paternal inheritance of mtDNA is revitalized in healthy people. In three independent families and moreover, several generations of these families, it was confirmed by DNA sequencing which was performed in two different laboratories. Luo et al sequenced mtDNA of several members of a family where many individuals were found to carry a high level of mtDNA heteroplasmy and suggested that inheritance of mtDNA was from both parents due to genetic trait. $^{5}$

The inheritance pattern as explained by Luo et al suggested that elimination of paternal mitochondria was due to a gene on one of the autosomes. ${ }^{5}$ This observation may be used to identify signal pathways which are responsible for paternal inheritance of mtDNA. ${ }^{6}$

An autologous gene signature was seen in 7 out of 11,035 trios. The allelic fraction was $5-25 \%$ and biparental inheritance was seen in $0.06 \%$ of offspring. On whole-genome sequencing, it was found that unique nuclear mtDNA segments ("mega-NUMTs") were transmitted by father in all these 7 families. These were $0.13 \%$ in fathers and this was an autosomal transmission of haplotype. It was concluded that rare paternal mtDNA heteroplasmy can be due to rare cryptic megaNUMTs (a large and rare mtDNA segment). ${ }^{7}$ 
These 11,035 were unrelated mother-fatheroffspring trios. In 10,764 trios, the father harbored at least one variant (Allelic fraction $>5 \%$ ) which was not detected in the mother. It was observed that seven fathers-off springs pairs were carrying NUMT with two breakpoints on the mtDNA sequence, 500 bp away from each other. The same mega rare NUMT was observed in one mother in a different family and subsequently her child also carried it. Both of them were carrying the same haplotype allelic fraction. ${ }^{7}$ As these families were unrelated, the inheritance of rare NUMT in mixed haplotype adds more weightage to the argument of paternal inheritance.

\section{References}

1. Vissing J. Paternal comeback in mitochondrial DNA inheritance. PNAS. 2019; 16(5): 1475-6. Doi: 10.1073/pnas.1821192116

2. DeLuca SZ, O'Farrell PH. Barriers to male transmission of mitochondrial DNA in sperm development. Dev Cell. 2012; 22(3): 660-8. Doi: 10.1016/j.devcel.2011. 12.021
3. McWilliams TG, Prescott AR, Montava-Garriga L, Ball $G$, Singh F, Barini $E$, et al. Basal mitophagy occurs independently of PINK1 in mouse tissues of high metabolic demand. Cell Metab. 2018; 27(2): 439-49. e5. Doi: 10.1016/j.cmet.2017.12.008

4. Radzvilavicius AL, Lane N, Pomiankowski A. Sexual conflict explains the extraordinary diversity of mechanisms regulating mitochondrial inheritance. BMC Biol. 2017; 15(1): 1-2. Doi: 10.1186/s12915-0170437-8

5. Luo S, Valencia CA, Zhang J, Lee NC, Slone J, Gui B, Wang X, Li Z, Dell S, Brown J, Chen SM. Biparental inheritance of mitochondrial DNA in humans. PNAS. 2018; 115(51): 13039-44. Doi: 10.1073/pnas.1810 946115

6. Rius R, Cowley MJ, Riley L, Puttick C, Thorburn DR, Christodoulou J. Biparental inheritance of mitochondrial DNA in humans is not a common phenomenon. Genet Med. 2019; 21(12): 2823-26. Doi: 10.1038/s41436-019-0568-0

7. Wei W, Pagnamenta AT, Gleadall N, Sanchis-Juan A, Stephens J, Broxholme J, Tuna S, Odhams CA, Fratter C, Turro E, Caulfield MJ. Nuclear-mitochondrial DNA segments resemble paternally inherited mitochondrial DNA in humans. Nat Commun. 2020; 11(1): 01. Doi: 10.1038/s41467-020-15336-3 